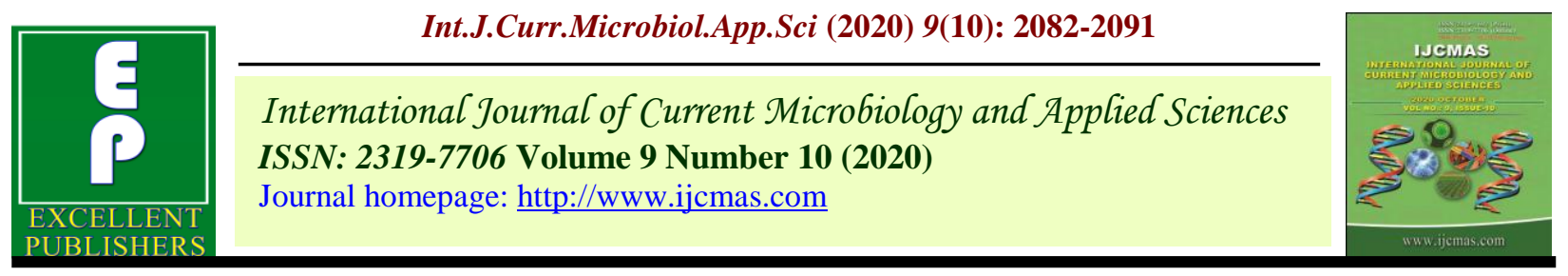

Original Research Article

https://doi.org/10.20546/ijcmas.2020.910.253

\title{
A Study on Nutritional Status of Tribal Families of Vizianagaram District, India
}

\author{
Bilquis*, A. Neelima and M. A. Vihari \\ Dept. Human Development and Family Studies, College of Community Science, \\ ANGRAU, Guntur, India \\ *Corresponding author
}

\section{A B S T R A C T}

\begin{tabular}{|l|}
\hline Keyw or d s \\
$\begin{array}{l}\text { Nutritional status, } \\
\text { Tribal families }\end{array}$ \\
\hline Article Info \\
\hline $\begin{array}{l}\text { Accepted: } \\
\text { 17 September } 2020 \\
\text { Available Online: } \\
10 \text { October } 2020\end{array}$ \\
\hline
\end{tabular}

Tribal populations are socio-economically disadvantaged compared to other population groups. They have different health problems owing to the variability in their geographical, socio-economic development and cultural characteristics. A cross sectional survey was carried out by Krishi Vigyan Kendra, Rastakuntubai to assess the dietary pattern and nutritional status of tribal population in selected tribal villages of Vizianagaram district of Andhra Pradesh. In Vizianagaram district there are about 8 tribal mandals having different types of tribes like Jathapu, Savara, Gadaba, Kondadora, Gondu, Mali etc. The study was done in four tribal villages Durbili, Suryanagaram, Shantinagaram, and Vanjarapuguda to identify the Nutritional status of the tribal families and studying the dietary pattern of the tribal families. The sample comprised of 450 tribal people. Results revealed that children below 6 years were formed to be undernourished, adolescent girls found to be anaemic, pregnant and lactating women were found to be underweight and anaemic due to micronutrient deficiencies in their diets.

\section{Introduction}

Nutrition is the science that interprets the interaction of nutrients and other substances in food in relation to maintenance, growth, reproduction, health and disease of an organism. It includes food intake, absorption, assimilation, biosynthesis, catabolism, and excretion. The diet of an organism is what it eats, which is largely determined by the availability and palatability of foods. For humans, a healthy diet includes preparation of food and storage methods that preserve nutrients from oxidation, heat or leaching, and that reduces risk of food borne illnesses.
India has high rate of under nourished population with marginal improvement in situation in last 25 years. The prevalence of underweight, stunted and wasted is higher in tribal and rural areas than urban. The progress on other parameters of the nutritional status such as level of anemia in population groups and birth weight of newborns is also slow in the tribal community. India had a series of initiatives and programmes since independence which focused on improving nutritional status of the population. Malnutrition refers to deficiencies, excesses or imbalances in a person's intake of energy and/or nutrients. 'Under-nutrition' - which 
includes stunting (low height for age), wasting (low weight for height), underweight (low weight for age) and micronutrient deficiencies or insufficiencies (lack of important vitamins and minerals).

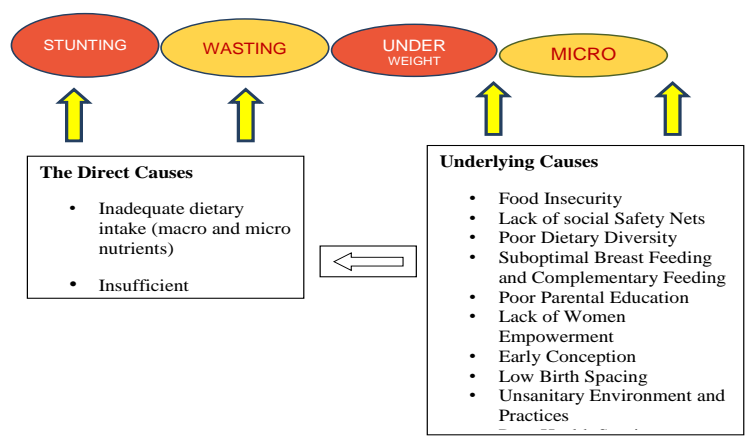

There has been some progress on improving nutritional status of tribal population in India. A few measures taken are integrated health and nutrition initiatives with closer collaboration of ITDA, health, women and child development and education departments. Diversification of supply of food under government programmes including more nutritious items such as millets, eggs, milk, soyabean and nutrient rich fresh foods and promote nutrition garden concept. Government of Andhra Pradesh has recognized nutrition as a development priority and initiated the State Mission for Nutrition in 2016, for a period of 10 years ending 2026.

The main objectives include to study the dietary pattern of the tribal families and to study the nutritional status of tribal families.

\section{Materials and Methods}

The study was conducted in Vizianagaram district. It is a cross-sectional study conducted in 4 tribal villages of Vizianagaram district namely Durbili, Suryanagram, Shantinagaram, and Vanjarapuguda. The respondents were selected by random sampling method. Multistage simple random sampling technique was applied to select villages. A schedule was developed to carry out the survey Prior consent was taken from selected below 6 years children, pregnant \& lactating women and elder persons. Information was also collected awareness about different types of food groups, cooking methods and food fads and falsies all the family members were interviewed about the dietary intake using the 24 hour recall method. Anthropometric measurements such as height\& weight were measured. Health status data was taking from the local Anganwadi centers and Health centers.

\section{Results and Discussion}

Table 1 shows that in Durbili majority (37.50\%) of the sample were elderly followed by children below 6 years $(26 \%)$, adolescents (20\%), lactating mothers (9\%) and pregnant women $(7.50 \%)$. In case of Suryanagaram majority $(30 \%)$ of the samples were children below 6 years followed by adolescents $(28 \%)$, elderly (24\%), pregnant women $(10 \%)$ and lactating mothers (8\%). In Shantinagaram majority $(30 \%)$ of the samples were children below 6 years followed by adolescents $(28 \%)$, elderly (24\%), lactating mothers (10\%) and pregnant women (8\%). As far as Vanjarapuguda is concerned majority (40\%) were children below 6 years followed by elderly (24\%), adolescents (20\%), lactating mothers (10\%) and pregnant women (6\%) fig. 1.

Equal per cent of the samples were elderly $(30 \%)$ and children below 6 years (30\%) followed by adolescents (23\%), lactating mothers $(9 \%)$ and pregnant women $(8 \%)$ fig. 2.

Table 2 shows the nutritional status of the children below 6 years of age. Majority (36.54\%) of the children below 6 years of age in Durbili were stunted followed by wasted (23.08\%), underweight $(21.15 \%)$ and normal 
(19.23\%). As far as Suryanagaram is concerned majority of the children below 6 years of age were normal $(46.67 \%)$ followed by equal number of children were wasted $(20 \%)$ and underweight $(20 \%)$ then stunted (13.33\%). In Shantinagaram majority of the children below 6 years of age were normal (46.67\%) followed by underweight (26.67) and equal number of children were stunted $(13.33 \%)$ and wasted (13.33\%). In Vanjarapuguda majority of the children were normal $(50 \%)$ followed by stunted $(20 \%)$ and equal number of children were underweight $(15 \%)$ and wasted $(15 \%)$.

Figure 4 shows that 37 per cent of the total sample was normal, 24 per cent were stunted, 20 per cent were underweight and 19 per cent were wasted. The main reason for this is prolonged breast feeding. Children are breast fed till two years without giving proper supplementary foods. Another important reason is majority of the mothers are adolescents as child marriage is common in the tribal culture.

Adolescent mothers who are anemic and malnourished give birth to the low birth weight, stunted children. After two years also children are not provided with nutri rich foods. The tribal diet is starch based as the climate is suitable to grow tubers like yam and sweet potato.

Table 3 reveals that more than half of the samples in Durbili (60\%), Suryanagaram $(60 \%)$ and Vanjarapuguda $(66.67 \%)$ were normal while half of the pregnant women in Shantinagaram (50\%) were normal. While 40 per cent of pregnant women were anemic in both Durbili and Suryanagarm, 50 percent in Shantinagaram and around 33 percent of pregnant women were anemic. Anemia and folic acid deficiencies are common in tribal pregnant women. Tribals cultivate and eat finger millet (Ragi) which is rich in iron and calcium. This is the only source of iron for them. They don't eat green leafy vegetables, carrots and papaya during pregnancy. Milk consumption was also found to be nil as tribal culture does not permit to take milk from cows. The whole milk is left to the calf only.

Nutritional status of lactating mothers is represented in table 4. Majority of the lactating mothers of Durbili (72.22\%), Suryanagaram (62.50\%), and equal percentage of the lactating mothers in Shatinagaram (60\%) and Vanjarapuguda $(60 \%)$ were normal. Around 28 per cent in Durbili, 37 per cent in Suryanagaram, 40 percent each in Shanitinagaram and Vanjarapuguda were anemic. The lactating mothers also are anemic and deficient in calcium. Women do not consume milk and milk products which are a requirement during this period. Prolonged breast feeding and calcium deficiencies are resulting in osteoporosis and arthritis problems at very young age.

With regard to nutritional status of adolescents majority of the adolescents in Durbili (62.50\%), Suryanagaram (64.29\%), Shantinagaram $(71.43 \%)$ and Vanjarapuguda $(60 \%)$ were normal. It was also revealed that around 38 per cent of adolescents in Durbili, 36 per cent in Suryanagaram, 29 per cent in Shantinagaram and 40 per cent in Vanjarapuguda were anemic (Table 5).

Adolescents in tribal areas have iron deficiency coupled with other micro nutrient deficiencies like calcium, zinc and folic acid. Adolescents get married immediately after attaining menarche at the age of 11 to 12 years. The average age of adolescents during their first pregnancy is 14 years. 
Table.1 Sample distribution $\mathrm{N}=450$

\begin{tabular}{|c|c|c|c|c|c|c|c|c|c|c|c|}
\hline \multirow[t]{2}{*}{ Village } & \multicolumn{2}{|c|}{$\begin{array}{c}\text { Below } 6 \\
\text { years }\end{array}$} & \multicolumn{2}{|c|}{ Pregnant } & \multicolumn{2}{|c|}{$\begin{array}{c}\text { Lactating } \\
\text { mothers }\end{array}$} & \multicolumn{2}{|c|}{ Adolescents } & \multicolumn{2}{|c|}{ Elderly } & \multirow{2}{*}{$\begin{array}{c}\text { Total } \\
\mathrm{f}\end{array}$} \\
\hline & $\mathrm{f}$ & $\%$ & $\mathrm{f}$ & $\%$ & $\mathrm{f}$ & $\%$ & $\mathrm{f}$ & $\%$ & $\mathrm{f}$ & $\%$ & \\
\hline Durbili & 52 & 26.00 & 15 & 7.50 & 18 & 9.00 & 40 & 20.00 & 75 & 37.50 & 200 \\
\hline Suryanagaram & 30 & 30.00 & 10 & 10.00 & 08 & 8.00 & 28 & 28.00 & 24 & 24.00 & 100 \\
\hline Shantinagaram & 15 & 30.00 & 04 & 8.00 & 05 & 10.00 & 14 & 28.00 & 12 & 24.00 & 50 \\
\hline Vanjarapuguda & 40 & 40.00 & 06 & 6.00 & 10 & 10.00 & 20 & 20.00 & 24 & 24.00 & 100 \\
\hline Total & 137 & 30.44 & 35 & 7.78 & 41 & 9.11 & 102 & 22.67 & 135 & 30.00 & 450 \\
\hline
\end{tabular}

Table.2 Nutritional status of children below 6years of age $n=137$

\begin{tabular}{|l|c|c|c|c|c|c|c|c|c|}
\hline \multirow{2}{*}{ Village } & \multicolumn{2}{|l|}{ Stunted } & \multicolumn{2}{l|}{ Wasted } & \multicolumn{2}{|c|}{ Underweight } & \multicolumn{2}{l|}{ Normal } & Total \\
\cline { 2 - 12 } & $\mathbf{f}$ & $\mathbf{\%}$ & $\mathbf{f}$ & $\mathbf{\%}$ & $\mathbf{f}$ & $\mathbf{\%}$ & $\mathbf{f}$ & $\mathbf{\%}$ & \\
\hline Durbili & 19 & 36.54 & 12 & 23.08 & 11 & 21.15 & 10 & 19.23 & 52 \\
\hline Suryanagaram & 04 & 13.33 & 06 & 20.00 & 06 & 20.00 & 14 & 46.67 & 30 \\
\hline Shantinagaram & 02 & 13.33 & 02 & 13.33 & 04 & 26.67 & 07 & 46.67 & 15 \\
\hline Vanjarapuguda & 08 & 20.00 & 06 & 15.00 & 06 & 15.00 & 20 & 50.00 & 40 \\
\hline Total & 33 & 24.09 & 26 & 18.98 & 27 & 19.71 & 51 & 37.23 & 137 \\
\hline
\end{tabular}

Table.3 Nutritional status of pregnant women $n=35$

\begin{tabular}{|l|c|c|c|c|l|}
\hline Village & \multicolumn{2}{|l|}{ Normal } & \multicolumn{2}{l|}{ Anemic } & Total \\
\hline Durbili & f & $\mathbf{\%}$ & $\mathbf{f}$ & $\boldsymbol{\%}$ & \\
\hline Suryanagaram & 09 & 60.00 & 06 & 40.00 & 15 \\
\hline Shantinagaram & 02 & 60.00 & 04 & 40.00 & 10 \\
\hline Vanjarapuguda & 04 & 66.00 & 02 & 50.00 & 04 \\
\hline Total & 21 & 60.00 & 14 & 40.02 & 06 \\
\hline
\end{tabular}

Table.4 Nutritional status of lactating mothers $n=41$

\begin{tabular}{|l|c|c|c|c|c|}
\hline \multirow{2}{*}{ Village } & \multicolumn{2}{|c|}{ Normal } & \multicolumn{2}{c|}{ Anemic } & Total \\
\hline Durbili & f & $\mathbf{\%}$ & f & $\mathbf{\%}$ & \\
\hline Suryanagaram & 13 & 72.22 & 05 & 27.78 & 18 \\
\hline Shantinagaram & 05 & 62.50 & 03 & 37.50 & 08 \\
\hline Vanjarapuguda & 03 & 60.00 & 02 & 40.00 & 05 \\
\hline Total & 06 & 60.00 & 04 & 40.00 & 10 \\
\hline
\end{tabular}


Int.J.Curr.Microbiol.App.Sci (2020) 9(10): 2082-2091

Table.5 Nutritional status of Adolescents $n=102$

\begin{tabular}{|l|l|l|l|l|l|}
\hline \multirow{2}{*}{ Village } & \multicolumn{2}{|l|}{ Normal } & \multicolumn{2}{l|}{ Anemic } & Total \\
\cline { 2 - 7 } & f & \% & f & \% & \\
\hline Durbili & 25 & 62.50 & 15 & 37.50 & 40 \\
\hline Suryanagaram & 18 & 64.29 & 10 & 35.71 & 28 \\
\hline Shantinagaram & 10 & 71.43 & 04 & 28.57 & 14 \\
\hline Vanjarapuguda & 12 & 60.00 & 08 & 40.00 & 20 \\
\hline Total & 65 & 63.73 & 37 & 36.27 & 102 \\
\hline
\end{tabular}

Table.6 Nutritional status of Elderly $n=135$

\begin{tabular}{|l|c|c|c|c|l|}
\hline \multirow{2}{*}{ Village } & \multicolumn{2}{|l|}{ Normal } & \multicolumn{2}{l|}{ Anemic } & Total \\
\cline { 2 - 6 } & f & \% & f & \% & \\
\hline Durbili & 49 & 65.33 & 26 & 34.67 & 75 \\
\hline Suryanagaram & 16 & 66.67 & 08 & 33.33 & 24 \\
\hline Shantinagaram & 08 & 66.67 & 04 & 33.33 & 12 \\
\hline Vanjarapuguda & 14 & 58.33 & 10 & 41.67 & 24 \\
\hline Total & 87 & 64.44 & 48 & 35.56 & 135 \\
\hline
\end{tabular}
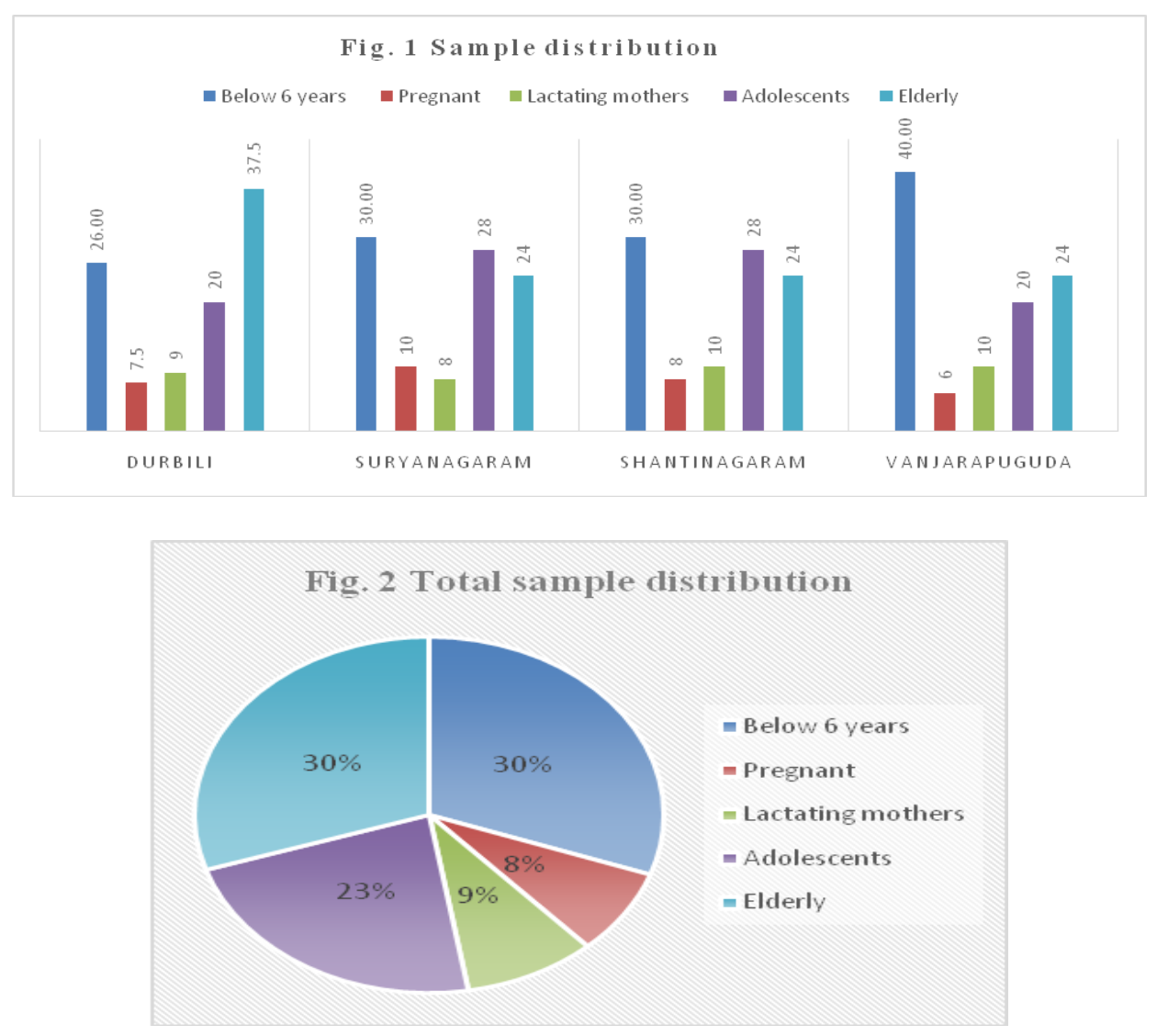
Int.J.Curr.Microbiol.App.Sci (2020) 9(10): 2082-2091

Fig. 3 Nutritional status of children below 6years of age
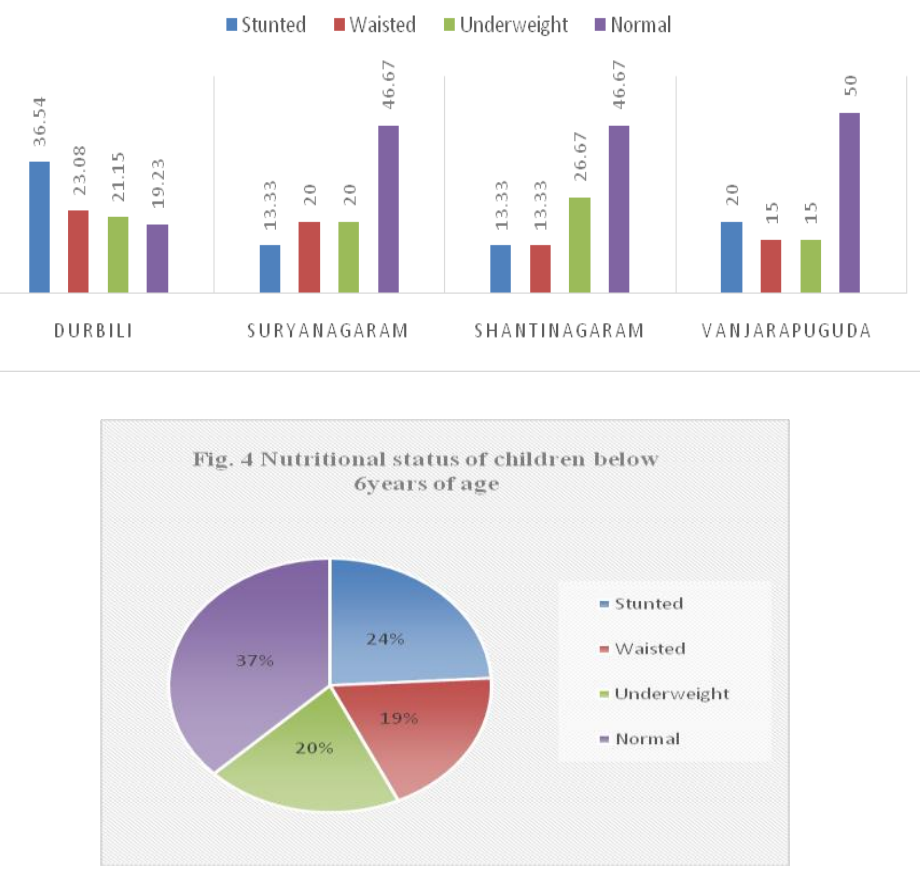

FIG. 5 Nutritional status of pregnant women

normal anemic

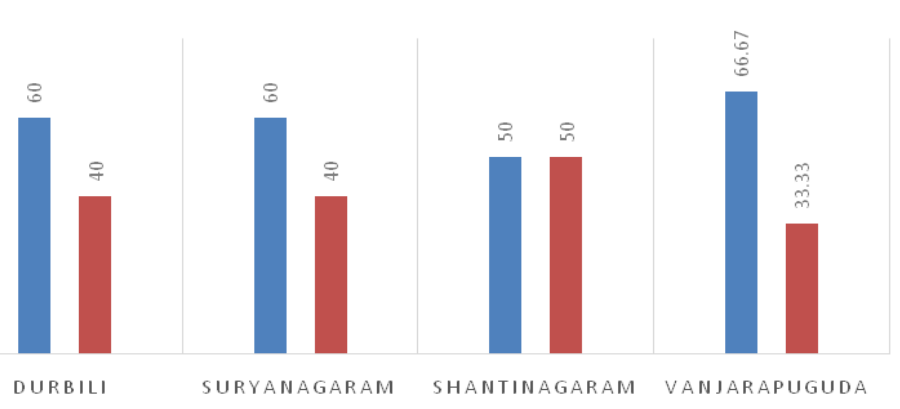

Fig. 6

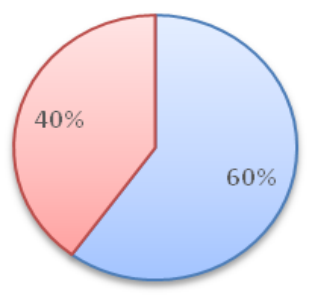

$\square$ Normal $\square$ Anemic 


\section{Int.J.Curr.Microbiol.App.Sci (2020) 9(10): 2082-2091}
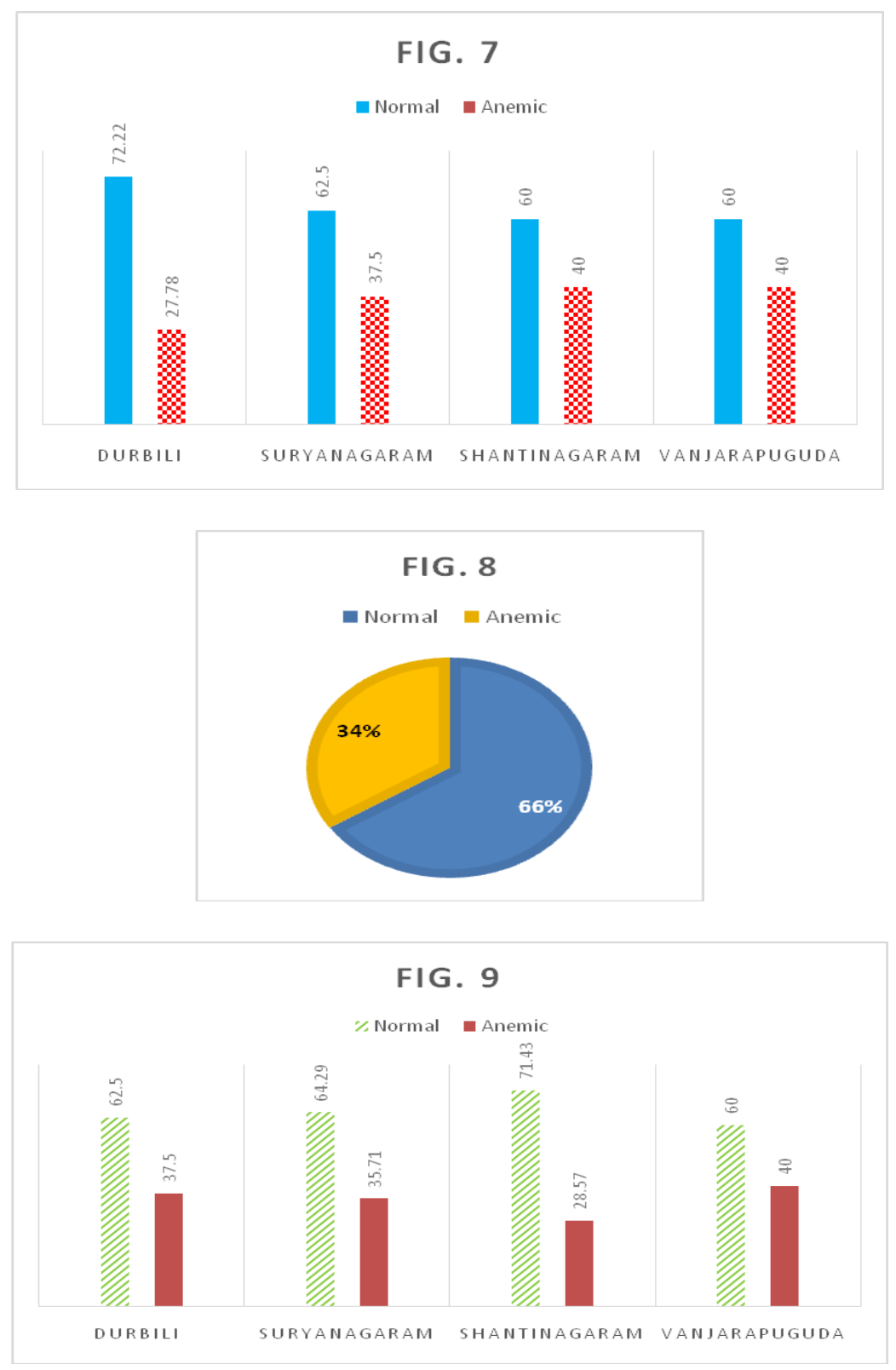

FIG. 10

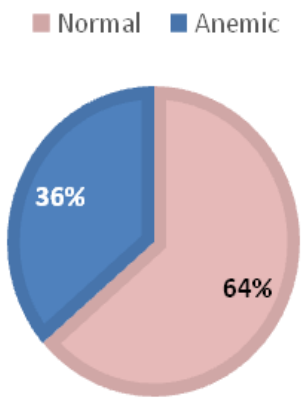



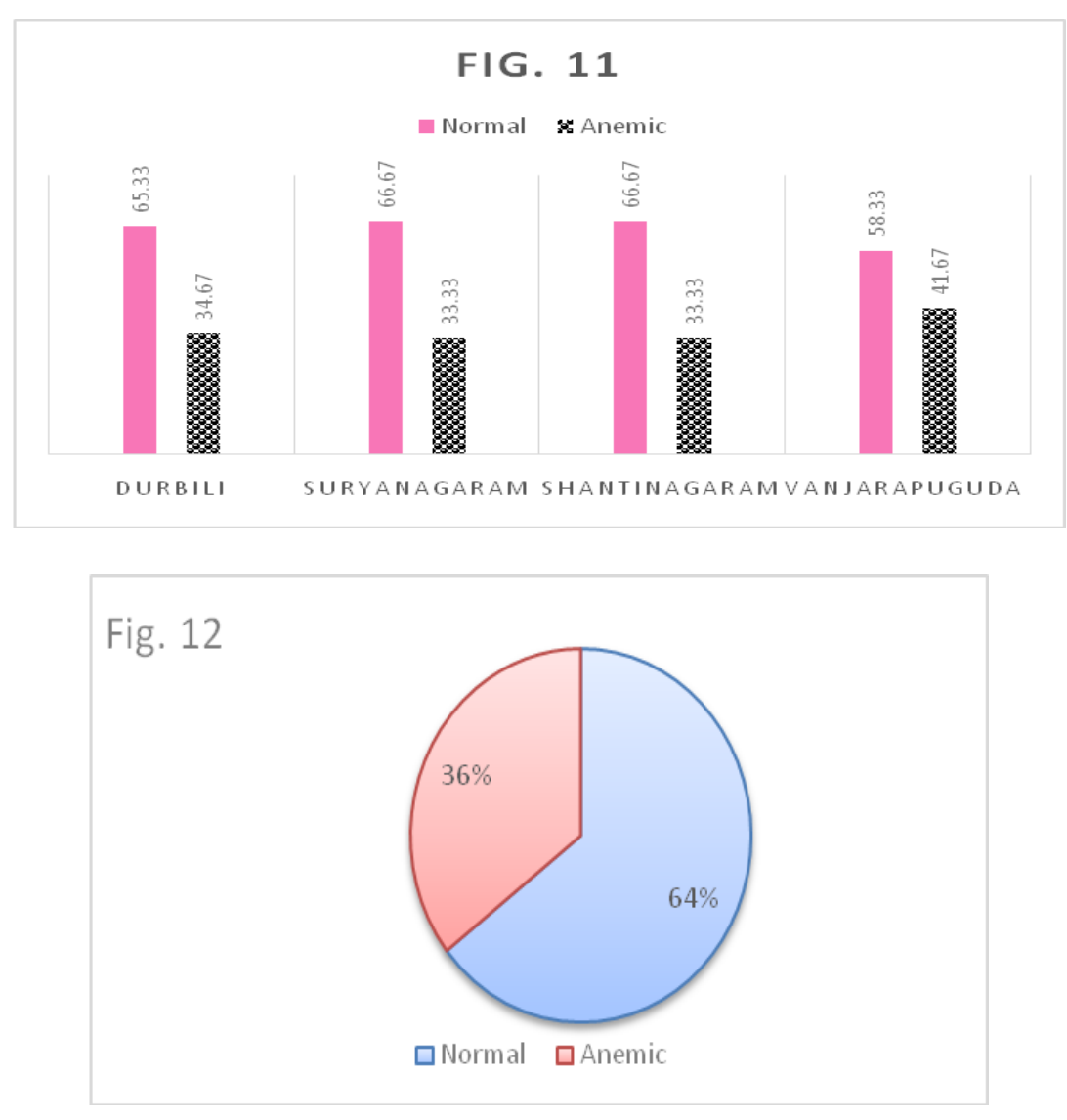

Nutritional status of elderly id represented in table 6. It was found that more than half of the elderly samples in Durbili (65.33\%), Suryanagaram (66.67\%), Shantinagaram (66.67\%) and Vanjarapuguda (58.33\%) were normal. About 35 per cent of elderly samples in Durbili, 33 per cent in suryanagaram, 33 per cent in Shantinagaram and 41.67 per cent in Shantinagaram were anemic. Elder adults were also found to be anemic and had micro nutrient deficiencies. The diets are basically carbohydrate rich and deficient in vitamins and minerals. It was found that intake of fruits and vegetables were less among the tribal community. Calcium deficiencies are common.

The consolidated data of nutritional status indicated that following inferences

Majority of the tribal children who are below 6 years were formed to be undernourished and having nutritional deficiencies like anaemia, B complex, vitamin $\mathrm{C}$, calcium deficiency.

Majority of the pregnant and lactating women were formed to be underweight and anaemic few months were having calcium deficiencies as well.

The adolescent girls were found to be anaemic and underweight irrespective of genders.

The elderly persons were also suffering with nutritional deficiencies and health problems.

It was found that weaning foods are given to the young children only after 1 year of age till then the child is completely breast feed.

Majority of the tribal women do not have the knowledge of the types of foods to be given to the young children, the food that is cooked for the family is being fed to the children no special foods are given. 
Majority of the tribal families do not consume milk and milk products which is related to their cultural factor not taking the milk from the cattle in a group which is leading to protein and calcium deficiency.

It was found that the consumption of green leafy vegetables was minimum to meal in their daily diets.

Majority of the tribal families grow vines and tubers in their backyards and consume the same every day.

The diet consumption of the tribal families comprises of cereals and pluses based. Millets consumption is minimum to nil. Though the tribal families grow finger millet the consumption is limited to found in few age groups.

It was found that the children are not given any home cooked snakes and have the habit of having the processed foods from local markets which are not safe and hygienic.

The tribal families have the habit of straining the pattern from the cooked rice and it is fed to the cattle. Majority of them do not have the knowledge of healthy cooking practices minimizing cooking nutrient losses.

The cooking oil used in the tribal families was palm oil, sunflower oil, besides using locally extracted oil from mahuva plant seeds.

It was found that tribal families minimum of dry fruits that is cashew. Though the tribal areas grow cashew orchards all the produce is sold without giving importance to the family consumption.

The carrot and beetroot consumption was also found to be very less.

Lactating mothers are given gongura, palak, longbeans, brinjal, milk, groundnut and jaggery chekki, eggs, chicken, ragi malt, guava, coccinia.

Only when any family member is sick and notable to consume rice, chapathis made with wheat flour are given.
Starch rich foods like colacasia, cassava, sweet potato, potato all consumed most of the time, other vegetables include long beans, brinjal and ladies finger.

Majority of the people eat guava and cluster apple among the fruits.

Comparatively non-vegetarian foods are taken in more quantity that the vegetables and greens.

In conclusion the tribal people are known for their culture and traditions. Majority of the tribal population have rich indigenous technical knowledge which they apply for their day to day life. Though there is information available on nutri rich foods and importance of balanced diets through local Anganwadi centers of ICDS project, tribal families are reluctant to follow due to illiteracy and ignorance. But changes are being observed due to repeated orientation and awareness programmes on health and nutrition especially to the vulnerable groups. There is a need for innovative approaches to create awareness about the importance of balanced foods and nutritional status of children in their local language through folk arts and street plays. Tribal diets need to be enriched with nutri rich foods. This is possible only when their farming systems change to meet the nutritional needs of tribal families.

\section{References}

Kupputhai U, Mallika N. Nutritional status of adult women Belonging to Khond, Gadaba and Porja Tribes of Andhra Pradesh. Indian J Nutr Diet. 1993; 30(7): 173-9.

Ghosh S, Malik SL. Sex differences in body size and shape among santhals of west bengal. Anthropologist. 2007; 9(2): 1439.

Haque MM, AkterJ, Ahmed K R, Chowdhury HA, Hossain S, Tripura NB. Nutritional 
status of settler and indigenous women of reproductive age group in Khagrachari District, Bangladesh, J Enam Med Col. 2014; 4(2): 98-101.

Suraj SH, Ghritlahre M, Das S. Nutritional status among females of bhaina tribe of Bilaspur, Chhattisgarh, India: An Anthropological Insight. Journal of Anthropology. 2014:7. Article ID 897893.

Jayatissa R, Hossain M, Nanayakkara L. Assesment of nutritional status and assosciated factors in Northern Province. Srilanka. Medical Research Institute in collaboration with UNICEF and WFP. 2012: 1-73.

Goswami M, Dash B, Dash NC. Traditional method of reproductive health care practices and fertility control among the bhumija tribe of Baleswar, Orissa. Ethno Med. 2011; 5(1): 51-5.

Subal Das, Mileva Mahata, Kaushik Bose. Nutritional profile of adult birhors of purulia: a particularly vulnerable tribal group of West Bengal, India. Asian Academic Research Journal of Multidisciplinary. 2013; 1(5): 262-76.

Laxmaiah A, Mallikharjuna Rao K, Hari Kumar R, Arlappa N, Venkaiah K, G.N.V. Brahmam. Diet and nutritional status of tribal population in ITDA Project Areas of Khammam District, Andhra Pradesh. J Hum Ecol. 2007; 21(2): 79-86.

National Nutrition Monitoring Bureau, Diet and Nutritional Status of Rural Population and Prevalence of Hypertension among adults in Rural Areas, NNMB Technical Report No.24, 2006. NNMB, NIN, Hyderabad.

Sreelakshmi PR, Vijaykuma K, Anish TS, Srinivas BM, Sheel S, Anita Abraham, Alice Mendez. Anaemia and Body Mass index of Non-pregnant tribal women of reproductive age group women in Palakkad district of Kerala, India. Indian J Prev Soc Med. 2102; 43(1): 35-41.

\section{How to cite this article:}

Bilquis, A. Neelima and Vihari, M. A. 2020. A Study on Nutritional Status of Tribal Families of Vizianagaram District. Int.J.Curr.Microbiol.App.Sci. 9(10): 2082-2091. doi: https://doi.org/10.20546/ijcmas.2020.910.253 